1. BDS, FCPS

Assistant Professor Oral Medicine

University College of Dentistry,

University of Lahore.

2. BDS, FCPS

Demonstrator Oral \& Maxillofacial Surgery

King Edward Medical University / Mayo Hospital Lahore.

3. BDS, FCPS

Lecturer Oral \& Maxillofacial Surgery University College of Dentistry, The University of Lahore.

4. BDS

Lecturer Oral \& Maxillofacial Surgery University College of Dentistry, The University of Lahore.

5. BDS, FCPS

Assistant Professor Oral \&

Maxillofacial Surgery

University College of Dentistry,

University of Lahore.

6. BDS, FCPS

Demonstrator Oral Medicine

University College of Dentistry,

University of Lahore.

Correspondence Address:

Dr. ljaz Ur Rehman

Department of Oral Medicine

University College of Dentistry,

University of Lahore.

ljaz.rahman@hotmail.com

Article received on:

12/09/2020

Accepted for publication:

30/04/2021

\section{Evaluation of the accuracy of ultrasonography compared to histopathological findings in diagnosis of infectious maxillofacial swellings.}

\begin{abstract}
ljaz Ur Rehman', Samreen Younas², Salman Amin³, Usman Tariq ${ }^{4}$, Tahmasub Faraz Tayyab5,
\end{abstract} Faiza Rehman ${ }^{6}$

ABSTRACT... Objective: To evaluate the accuracy of ultrasonography in diagnosis of infectious maxillofacial/swelling. Study Design: Simple Cross Sectional study. Setting: Outpatient Department of Oral and Maxillofacial Surgery Unit, Punjab Dental Hospital, Lahore. Period: February 2016 to August 2016. Material \& Methods: Conducted on 100 patients. The patients were evaluated with the ultrasound diagnostic modality. The ultrasound interpretation of all the cases was done and best possible diagnosis was made and recorded regarding diagnosis of infectious maxillofacial swellings. The incisional biopsy of every patient was done for histopathology. All findings of ultrasound and histopathology were entered to a proforma. Results: The average age of the patients was $35.81 \pm 14.31$ years. In this study, $63 \%$ patients were males and $37 \%$ were females. Out of 100 patients, $70(70 \%)$ patients had infectious swelling while $30(30 \%)$ did not have infectious swelling. The sensitivity of ultrasonography was calculated as $84.72 \%$, specificity was $67.86 \%$, positive predictive value was $87.14 \%$, negative predictive value was $63.33 \%$ and diagnostic accuracy was noted as $80 \%$ taking histopathology as gold standard. Conclusion: It was concluded from results of this study that ultrasonography has enough diagnostic accuracy to diagnose infectious swellings of maxillofacial region.

Key words: Histopathology, Incisional Biopsy, Infectious Swellings, Maxillofacial Region, Sensitivity.

Article Citation: ljaz Ur Rehman, Younas S, Amin S, Tariq U, Tayyab TF, Rehman F. Evaluation of the accuracy of ultrasonography compared to histopathological findings in diagnosis of infectious maxillofacial swellings. Professional Med J 2021; 28(12):1812-1816. https://doi.org/10.29309/TPMJ/2021.28.12.6075

\section{INTRODUCTION}

Head and Neck swellings are common in oral and maxillofacial region. ${ }^{1}$ Because of variety of lesions existing in this region diagnosis is a complex process. ${ }^{2}$ A definitive diagnosis of any disease or swellings is obtained with the help of various diagnostic aids like imaging laboratory and histopathological investigations etc. ${ }^{3}$

Ultrasonography has played a crucial role as a diagnostic and therapeutic modality in different medical and surgical specialties. Recently, it has been used for diagnosis in oral and facial region. ${ }^{4}$ It could be valuable in identifying various maxillofacial swellings such as inflammatory swellings, salivary glands diseases and lymph nodes, cysts, neoplasm etc. ${ }^{5}$ Principle of ultrasound is to generate electrical impulses which then convert into high frequency sound waves and then transmit to the targeted tissues through a transducer. ${ }^{6}$

Ultrasound is widely used in most part of the world as a routine diagnostic and in diagnosing maxillofacial swellings but no idea is available regarding its use in Pakistan in same specialty. In Pakistan different results are expected as compared to other western countries because of poor oral hygienic conditions increased used of pan separi leading to increase susceptibility to different oral and maxillofacial swellings. ${ }^{12}$ The rationale of the present study is to evaluate the accuracy of ultrasound modality to diagnose different swellings of the oral and maxillofacial region. So that we can use the ultrasonography as a routine diagnostic tool as it is more readily available in the hospital and it is inexpensive, noninvasive and easily reproducible. ${ }^{7}$

The main aim of our study was to evaluate 
the accuracy of ultrasonography findings as compared to histopathological findings to diagnose various infectious oral and maxillofacial swellings.

\section{MATERIAL \& METHODS}

This cross sectional study was conducted from February 2016 to August 2016 at outpatient department of Oral and Maxillofacial Surgery unit, Punjab Dental Hospital, Lahore. Sample size of estimated 100 cases using 95\% confidence level with an expected prevalence of infectious MS i.e. $43 \%$ taking sensitivity of ultrasound $65 \%$ with margin of error $12 \%$ and specificity $80 \%$ with $9 \%$ margin of error. All cases were included through Non-probability, purposive sampling. Patients of both gender and any age presenting with maxillofacial swelling which were assessed on clinical examination and panoramic radiograph were included. Medically compromised patients (Diabetes mellitus, Hypertension and tuberculosis etc) which were assessed on history and clinical examination were excluded.

Informed consent was obtained. All patients were evaluated with the ultrasound diagnostic tool using a linear transducer operating at a frequency of $8-12 \mathrm{mHz}$. The ultrasound interpretation of all the cases was done by a single operator who was the senior registrar and best possible diagnosis was made and recorded regarding diagnosis of infected maxillofacial swelling. On Ultrasound, positive (Infective) echogenicity's of tissues are higher than normal. Negative (Non infective) echogenicity of tissues are same as adjacent structure. The incisional biopsy of every patient was done by the researcher under supervision and sent to histopathology laboratory of Shaukat Khanum cancer hospital and research center Lahore. Histopathologist did not have any previous ultrasonological results. On histopathology, Positive (Infective) acute and chronic inflammatory cells are present. Negative (Non inflammatory) acute and chronic inflammatory cell are absent. All findings of ultrasound and histopathology were entered to the proforma.
Data was entered and analysed using SPSS version 14. Categorical variable like Gender was categorized in terms of frequency and percentage. Continuous variable like age was categorized in the form of mean $\pm S D$. A $2 \times 2$ contingency table was generated and sensitivity, specificity, positive and negative predictive values were included.

\section{RESULTS}

A total of 100 patients were included in our study. The mean age of the patients was $35.81 \pm 14.31$ years while minimum and maximum age of respondents was 12 and 60 years respectively. Table-I

Of 100 patients $63 \%$ were males and $37 \%$ were females. The male to female ratio was 1:0.7. Figure-1.

The study results showed that $14(14 \%)$ patients appeared with cellulitis diagnosis, 10(10\%) appeared with garrs osteomyelitis, 3(3\%) with lymphadentis, 22(22\%) with osteomyelitis, $16 \%$ with parotitis and periapical cyst respectively, $6(6 \%)$ with sialadenitis, $8(8 \%)$ with sialoadenitis and $5(5 \%)$ patients appeared with sinusitis diagnosis. Figure-1.

The study results showed that $70(70 \%)$ patients were detected with ultrasonography and $30(30 \%)$ were not detected with ultrasonography.

The study results showed that 72 (72\%) patients were detected with histopathology and 28 were not detected with histopathology.

Out of 100 patients, the sensitivity of ultrasonography was noted as $84.72 \%$, specificity $67.86 \%$, positive predictive value $87.14 \%$, negative predictive value was $63.33 \%$ and diagnostic accuracy was $80 \%$ taking histopathology as gold standard. 


\begin{tabular}{|l|c|}
\hline \multicolumn{1}{|c|}{ Age } & $35.81 \pm 14.31$ \\
\hline Male & $63(63 \%)$ \\
\hline Female & $37(37 \%)$ \\
\hline Ultrasound findings & $70(70 \%)$ \\
\hline Positive & $30(30 \%)$ \\
\hline Negative & \\
\hline Histopathological findings & $72(72 \%)$ \\
\hline Positive & $28(28 \%)$ \\
\hline Negative
\end{tabular}

Table-I. Study participants characteristics and findings. $(n=100)$

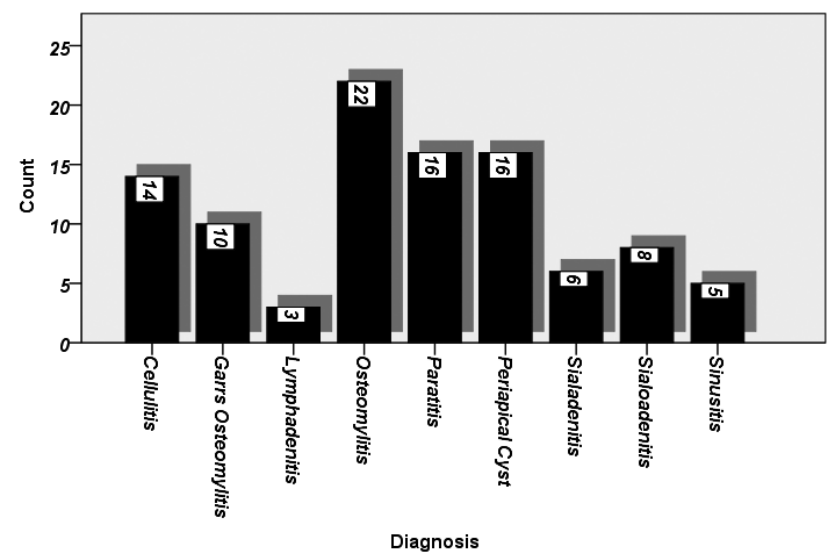

Figure-1. Frequency distribution about diagnosis of the patients.

\section{DISCUSSION}

The main aim of our study was to evaluate the accuracy of ultrasonography findings as compared to histopathological findings to diagnose various infectious oral and maxillofacial swellings.

Ultrasound with power Doppler was first used by Cotti in 2003 in the differential diagnosis of periapical lesions. ${ }^{9}$ Ultrasonography is a noninvasive modality that can have great value for prognosis of lesions, intraoperative scanning and differential diagnosis of different lesions and vascularization. $^{7}$

Pallagatti et al. (2012) reported that the ultrasonography provides accuracy for nature and extent of lesion in relation with the surrounding structures to diagnose maxillofacial sweelings. ${ }^{10}$ Another study done by Shivanand et al., revealed that total 40 patients were registered with 7 and
70 minimum and maximum ages in years. $62.5 \%$ were males and $37.5 \%$ were females. ${ }^{5}$ Our results are also consistent with Pallagatti and Shivannad, our findings showed the mean age of 35 in years and $63 \%$ were males and $37 \%$ were females.

Another study done by Bassiony et al., showed that ultrasonography is highly capable of detecting majority of the commonly involved facial space infections. Based on our results, USG has accurately detected $76 \%$ of all involved fascial spaces and $100 \%$ of involved superficial spaces. There was $100 \%$ agreement between Ultrasonography and Megnetic resonance imaging on 32 space infections, comprising 13 buccal, 10 submandibular, 5 canine, 2 submasseteric, 1 submental, and 1 infraorbital. ${ }^{3}$

The different lesions presenting in maxillofacial area have an altered and unique plan of management. Keeping this in view, it is essential to take a specific and precise facts of the underlying pathology as described by Peterson et al. (2003). 5,11

Soheyl Sheikh, et al. (2012) concluded in their study that USG found more significant findings as compare to histopathology. Likewise, they also obtained almost same results with clinical and radiological findings with contingency coefficient 0.895 and 0.889 respectively. Thus, the combination of clinical and radiological findings can be a best choice for diagnosis of oral and facial infectious swellings. ${ }^{10}$

Study conducted by Siva Venkataraman, et al. concluded that diagnostic value ultrasonography is gold standard for the oral and facial infectious swellings as compare to histopathology. ${ }^{12}$ Christensens et al. in 1988 found the significant role of ultrasonography in the musculoskeletal system intervention. ${ }^{13}$

Gray scale ultrasonography, an advanced and important diagnostic modality which is also valuable option to evaluate a variety of swellings of neck and maxillofacial areas. Ultrasound-guided biopsy is also beneficial with good specificity in this regard. ${ }^{14}$ Moreover, assessment of swelling 
with Doppler techniques can provide vascular information in the swelling area e.g. blood flow pattern in this. ${ }^{15,16}$

Howlettetal. (2004), Chandaketal.(2011), Ishikawa et al. (1983) and Nithya et al. (2003) established in their studies that with clinical examination, the ultrasonography should be taken as first tool for baseline diagnostic purpose due to lack of side effects, non-invasive, and easily available. The computed tomography and magnetic resonance imaging can be used as advance diagnostic tools to find the extension of swelling and tissue characteristics. ${ }^{17-21}$

Our study findings were also consistent with the above discussed studies. Our study results showed the sensitivity $84.72 \%$ with diagnostic accuracy of $80 \%$ of ultrasonography taking histopathology as gold standard in diagnosis of infectious maxillofacial swellings. The findings of our studies are in line with previous studies that USG is valuable diagnostic tool to detect swellings, especially in the superficial spaces of the head and neck. ${ }^{22,23}$ One study reported that ultrasound had enough sensitivity (92.30\%) and specificity (100\%) for diagnosis of infectious maxillofacial swellings. ${ }^{24}$ The findings of our study are contrasting from a study conducted by Panday et al. (2011) who reported that sensitivity of USG was $65 \%$ which is lower than our study. ${ }^{25}$

\section{CONCLUSION}

It was concluded from results of this study that ultrasonography has enough diagnostic accuracy to diagnose infectious swellings of maxillofacial region. Now we can recommend the use of ultrasonography as a routine diagnostic modality as it is more readily available in the hospital and it is inexpensive noninvasive and easily reproducible. This would now reduce excessive surgeries for biopsy.

\section{Copyright(C) 30 Apr, 2021.}

\section{REFERENCES}

1. Mallorie CN, Jones SD, Drage NA, Shepherd J. The reliability of high resolution ultrasound in the identification of pus collections in head and neck swellings. Int JOral Maxillofac Surg 2012; 41:252-5.
2. Kishore M, Alok A, Singh S, Kishore A,Panat SR, Sah VK. Efficacy of ultrasound in the diagnosis of swellings of orofacial region: An original research. J Indian Acad Oral Med Radiol 2020; 32:107-14.

3. Verma SK. Usefulness of ultrasonography in detection of swellings of head and neck region. J Adv Med Dent Scie Res 2016; 4(3):145-147.

4. Shah JS, Asrani VK. Clinical applications of ultrasonography in diagnosing head and neck swellings. J Oral Maxillofac Radiol 2017; 5:7-13.

5. Puri et al The Open Dentistry Journal, 2018, Volume 12.

6. Arslan ZB, Demir H, Berker Yıldız D, Yaşar F. Diagnostic accuracy of panoramic radiography and ultrasonography in detecting periapical lesions using periapical radiography as a gold standard. Dentomaxillofac Radiol 2020; 49: 20190290.

7. Rastogi A, Sharma K, Gauba N. Evaluation of efficacy of ultrasound in diagnosis of neck swellings. Int $\mathrm{J}$ Otorhinolaryngol Head Neck Surg 2018; 4: 169-75

8. Estrela C, Bueno MR, Leles CR, Azevedo B, Azevedo JR. Accuracy of cone beam computed tomography and panoramic and periapical radiography for detection of apical periodontitis. Journal of endodontics 2008; $34(3): 273-9$.

9. Gundappa M, $\mathrm{Ng} \mathrm{S}$, Whaites E. Comparison of ultrasound, digital and conventional radiography in differentiating periapical lesions. Dentomaxillofacial Radiology 2006; 35(5):326-33.

10. Pallagatti S, Sheikh S, Puri N, Mittal A, Singh B. To evaluate the efficacy of ultrasonography compared to clinical diagnosis, radiography and histopathological findings in the diagnosis of maxillofacial swellings. European Journal of Radiology 2012; 81(8):1821-7.

11. Peterson LJ, Ellis E, Hupp JR, Tucker MR. Contemporary oral and maxillofacial surgery: Mosby; 2003.

12. Azeem Akhtar et al Pak. J. Pharm. Sci., Vol.29, No.5(Suppl), September 2016, pp.1839-1846

13. Christensen R, Van Sonnenberg E, Casola G, Wittich G. Interventional ultrasound in the musculoskeletal system. Radiologic clinics of North America 1988; 26(1):145.

14. Wilson IR, Crocker EF. An introduction to ultrasonography in oral surgery. Oral surgery, oral medicine, oral pathology 1985; 59(3):236-41. 
15. Venkataraman SS, Aravind RJ, Kavin T. The role of diagnostic ultrasound as a new diagnostic aid in oral and maxillofacial surgery. Journal of pharmacy \& bioallied sciences 2012; 4(Suppl 2):S121.

16. McCann P, Brocklebank L, Ayoub A. Assessment of zygomatico-orbital complex fractures using ultrasonography. British Journal of Oral and Maxillofacial Surgery 2000; 38(5):525-9.

17. Howlett D, Alyas F, Wong K, Lewis K, Williams M, Moody $A$, et al. Sonographic assessment of the submandibular space. Clinical radiology 2004; 59(12):1070-8.

18. Chandak R, Degwekar S, Bhowte R, Motwani M, Banode $P$, Chandak M, et al. An evaluation of efficacy of ultrasonography in the diagnosis of head and neck swellings. Dentomaxillofacial Radiology 2011; 40(4):213-21.

19. Ishikawa $H$, Ishii $Y$, Ono $T$, Makimot $K$, Yamamoto $K$, Torizuka K. Evaluation of gray-scale ultrasonography in the investigation of oral \& neck mass lesions. J Oral Maxillofac Surg 1983; 40(4):213-21.
20. Nezafati S, Ghavimi M, Javad rashid R, Farhadi S, Dehnad V. Comparison of accuracy of computed tomography scan and ultrasonography in the diagnosis of mandibular fractures. Dent Res $\mathrm{J}$ 2020;17:225-30

21. Nithya C, Pandey M, Naik B, Ahamed IM. Patterns of cervical metastasis from carcinoma of the oral tongue. World J Surg Oncol 2003; 1(1):10.

22. Courtney MJ, Miteff A, Mahadevan M. Management of pediatric lateral neck infections: Does the adage never let the sun go down on undrained pus hold true? International journal of pediatric otorhinolaryngology 2007; 71(1):95-100.

23. Desser TS, Kamaya A. Ultrasound of thyroid nodules. Neuroimaging Clinics of North America 2008; 18(3):46378.

24. Mukhi $P$, Mahindra $U$. The use of ultrasonography in diagnosis and management of superficial fascial space infections 2012.

25. Pandey PK, Umarani M, Kotrashetti S, Baliga S. Evaluation of ultrasonography as a diagnostic tool in maxillofacial space infections. J Oral Maxillofac Res 2011;2:e4.

\begin{tabular}{|c|c|c|c|}
\hline \multicolumn{4}{|c|}{ AUTHORSHIP AND CONTRIBUTION DECLARATION } \\
\hline No. & Author(s) Full Name & Contribution to the paper & Author(s) Signature \\
\hline 1 & ljaz Ur Rehman & $\begin{array}{l}\text { Research, Conceptualization } \\
\text { Supervision \& reivew. }\end{array}$ & \\
\hline 2 & Samreen Younas & $\begin{array}{l}\text { Research, Conceptualization } \\
\text { Supervision \& reivew. }\end{array}$ & \\
\hline 3 & Salman Amin & $\begin{array}{l}\text { Introduction, Discussion } \\
\text { writing, Data collection and } \\
\text { Referencing. }\end{array}$ & \\
\hline 4 & Usman Tariq & $\begin{array}{l}\text { Literature review, data } \\
\text { collection and analysis, } \\
\text { manuscript draft. }\end{array}$ & \\
\hline 5 & Tahmasub Faraz Tayyab & $\begin{array}{l}\text { Literature review, data } \\
\text { collection and analysis, } \\
\text { manuscript draft. }\end{array}$ & \\
\hline 6 & Faiza Rehman & $\begin{array}{l}\text { Data analysis, Materials and } \\
\text { Methods, Results write up. }\end{array}$ & \\
\hline
\end{tabular}

